\title{
EDITOR'S NOTE: BLOSSOMS, PROJECT-BASED LEARNING AND ONLINE EDUCATION
}

\author{
John R. Bourne
}

Editor-in-Chief, International Journal on Innovation in Online Education (IJIOE)

\section{Donald Z. Spicer}

Editor-in-Chief, International Journal on Innovation in Online Education (IJIOE)

\section{A. Frank Mayadas \\ Editor-in-Chief, International Journal on Innovation in Online Education (IJIOE)}

KEY WORDS: BLOSSOMS, project-based learning, analytics

The article in this issue of IJIOE by Cammarata and Larson, titled "Project-Based Methods for Assessment of Active Learning STEM Video Lessons" has prompted the writing of this editorial. As outlined in the article the BLOSSOMS initiative at MIT is a decade old and has focused on improving STEM (Science, Technology, Engineering, and Math) Education through the creation of hundreds of interactive, inquiry-based videos, generated through an international consortium of practitioners. The article promotes the idea of coupling BLOSSOMS with project-based learning (PBL) to increase acceptability and uplift the teaching and learning of STEM, primarily to high school audiences. As the authors note in their article, BLOSSOMS by itself has proved hard to validate due to the lack of empirical evidence; the authors suggest that coupling project-based learning methods with BLOSSOMS is a way to secure validation.

A second article in this issue is by Bargotta, Finch, and Gunawardena, entitled "Using Real-Time Video Analytics to Improve Instruction." The key finding in this article is that one can use real-time analytics of the use of videos to improve instruction. The system described facilitates how students utilize a collection of videos providing the instructor with concrete analytics that can be used to improve student engagement and as a way of guiding teaching and learning. Based on a system that has been called a "Salon," the methodology works well for online education, utilizing the capability of enhancing group learning of noncollocated groups.

The editors believe that the two articles offer online educators an option to incorporate the ideas and methods of both of their articles into their courses if they see that as 
appropriate, since the two articles describe complementary approaches to the use of video materials. While neither article deals solely with online learning innovations, both describe very innovative approaches to education that should be part of an online educator's portfolio. Online videos can be important; especially, if well constructed, they can uplift the level of instruction. The PBL approach, complete with animations, simulations and expert human guidance adds a remarkable underlayment to STEM instruction. Likewise, the ability to measure student learning and activity using video materials will be of assistance to online instructors who are using videos as part of their instructional paradigm.

The central theme we wish to convey is that these articles offer the availability of both videos and attendant software for analyzing student use of videos. Both sets of authors offer free downloads. BLOSSOMS has a large collection of videos; the analytics article offers download of the implementation software for evaluating in real time the utilization of the videos. It seems logical that experiments with integration of the approaches outlined in the two articles could be important to the online learning community. For that reason, the editors have sought to draw your attention to this set of complementary ideas and implementations.

The editors of this journal feel that the approaches described are early stage, but innovative, and they could represent an important direction for online education at the high school level. We will look favorably toward publishing early results of experiments that link BLOSSOMS, PBL (or any other similar approaches), and online education.

We also plan to continue the practice, starting with this issue, of publishing interesting and potentially useful tools and techniques that were not developed specifically with online education in mind, but which could be of benefit to our readers. 